\title{
Physiological Demands of Running During Long Distance Runs and Triathlons
}

\author{
Christophe Hausswirth and Didier Lehénaff
}

Laboratory of Biomechanics and Physiology, French National Institute of Sport and

Physical Education (INSEP), Paris, France

\section{Contents}

Abstract.

1. The Uniqueness of the Triathlon.

2. Analysis of the Metabolic Constraints in Long Distance Running and Triathlons ..................................68 681

2.1 Parameters Relating to Dehydration: The Haematocrit ...................................................................68 681

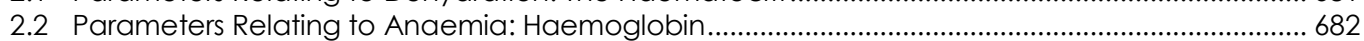

2.3 Parameters Relating to the Sympathetic Adrenergic System:

The Catecholamines

2.4 Endogenous Energy Reserves: Implications for Nutrition ............................................................683

2.5 Parameters Relating to Muscular Damage: Creatine Kinase, Lactate Dehydrogenase, Myoglobin..

3. Alterations in the Energy Cost of Running: A Comparative Analysis of Triathlons Versus Long Distance Running.....

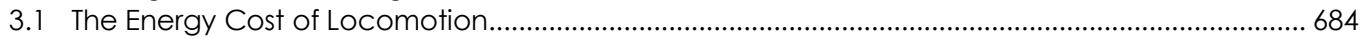

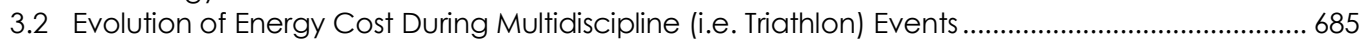

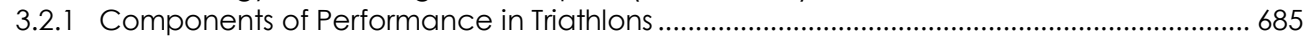

3.2.2 Comparison of the Energy Cost in Middle and Long Distance Running............................6 686

4. Conclusion.

Abstract
The aim of this review article is to identify the main metabolic factors which have an influence on the energy cost of running $(\mathrm{Cr})$ during prolonged exercise runs and triathlons. This article proposes a physiological comparison of these 2 exercises and the relationship between running economy and performance. Many terms are used as the equivalent of 'running economy' such as 'oxygen cost', 'metabolic cost', 'energy cost of running', and 'oxygen consumption'. It has been suggested that these expressions may be defined by the rate of oxygen uptake $\left(\dot{\mathrm{VO}}_{2}\right)$ at a steady state (i.e. between 60 to $90 \%$ of maximal $\dot{\mathrm{VO}}_{2}$ ) at a submaximal running speed.

Endurance events such as triathlon or marathon running are known to modify biological constants of athletes and should have an influence on their running efficiency. The $\mathrm{Cr}$ appears to contribute to the variation found in distance running performance among runners of homogeneous level. This has been shown to be important in sports performance, especially in events like long distance running. 
In addition, many factors are known or hypothesised to influence $\mathrm{Cr}$ such as environmental conditions, participant specificity, and metabolic modifications (e.g. training status, fatigue). The decrease in running economy during a triathlon and/or a marathon could be largely linked to physiological factors such as the enhancement of core temperature and a lack of fluid balance. Moreover, the increase in circulating free fatty acids and glycerol at the end of these long exercise durations bear witness to the decrease in $\mathrm{Cr}$ values. The combination of these factors alters the $\mathrm{Cr}$ during exercise and hence could modify the athlete's performance in triathlons or a prolonged run.

The emergence of new sports, such as triathlons (swimming, cycling, running), in which successive and prolonged efforts engage a variety of muscle groups, have led scientists and coaches to raise various questions about the physiological and/or biomechanical characteristics regulating these new disciplines. Widely perceived as an endurance sport, the triathlon apparently shares much with long distance running, ${ }^{[1,2]}$ but also claims its own specific-

ity. ${ }^{[3]}$ From a general approach, oxygen uptake $\left(\mathrm{VO}_{2}\right)$ appears to be a vital indicator of the athlete's ability to generate locomotive efforts of middle to long duration (triathlon, marathon, duathlon). More specifically, the performance achieved during prolonged exercise is dependent upon the relative contribution of a number of physiological factors actively involved in the continued execution of the movement.

Several attempts have been made to identify and describe the numerous parameters that may influence performance over various running ${ }^{[4]}$ and/or triathlon distances. ${ }^{[5]}$ Though constituting an im-

portant factor, maximal oxygen uptake $\left(\dot{\mathrm{VO}}_{2 \text { max }}\right)$ is only one of the parameters explaining successful performance in prolonged exercise. Several studies have demonstrated a wide range of performances

among populations displaying a similar $\dot{\mathrm{VO}}_{2 \max }$ or alternatively, equivalent performances from popu-

lations with dissimilar $\dot{\mathrm{V}}_{2 \max }$ values. ${ }^{[6,7]}$ It therefore seems that, although $\mathrm{VO}_{2 \max }$ is positively correlated with high level marathon ${ }^{[8]}$ and triathlon performance, ${ }^{[9]}$ this index cannot entirely account for the observed variations in performance. Other factors are classically considered to explain how high performances may be achieved with a rela- tively low $\dot{\mathrm{V}} \mathrm{O}_{2 \max }$. These include the capacity to use a high percentage of the $\dot{\mathrm{V}}_{2 \max }$ over extended periods of time, ${ }^{[10]}$ and the close relationship observed between performance time over middle and long distances and the speed corresponding to anaerobic threshold. ${ }^{[8]}$ However, an extensive analysis of the various correlations between these physiological parameters and performance is not sufficient to comprehensively explain successful performances.

In prolonged exercise, at sub-maximal workloads, the ability of an athlete to minimise their energy expenditure at a given intensity may be identified as one of the determinant factors of performance and used as a valid index of the athlete's efficiency. ${ }^{[11-13]}$ From this perspective, the concept of the energy cost in running (Cr) may be employed as another valid physiological parameter used to explain performance. Recent studies tend to indicate that this index may be predictive of run performance times in athletes having similar performances and/ or being highly trained ${ }^{[14]}$ or in recreational triathletes. ${ }^{[15]}$ Consequently, there is a general interest in using this index and a need to interpret its alterations.

The following review highlights the uniqueness of the triathlon, describes the metabolic constraints of triathlon and long distance running, and demonstrates the importance of the concept of $\mathrm{Cr}$ in both running and the triathlon. Finally, we shall try to make an exhaustive description of the factors that tend to improve the energy cost, and therefore, performance during prolonged exercise. 


\section{The Uniqueness of the Triathlon}

The triathlon can be defined as a combination of swimming, cycling and running performed in continuum and in that order. Since the 1980s, an increasing number of athletes ${ }^{[16]}$ and scientists ${ }^{[3,17,18]}$ have shown an interest in this exciting sport. Today moer than 2 million participants enjoy triathlons ranging from shorter recreational distances of 30 to 40 minutes duration to the spectacular Olympic triathlon or the gruelling Ironman long course lasting 8 to 12 hours. Recent and extensive worldwide development of the sport has highlighted a number of problems associated with optimisation of performance. This has led to research focused on evaluating the biomechanical and physiological constraints surrounding the triathlon. These include the ever-increasing training workloads involved, the complex training structure developed, and the difficulty in negotiating the in-race swim-to-bike and bike-to-run transitions.

Although biomechanical data on triathlon racing are limited, a number of studies ${ }^{[1,18-20]}$ have been conducted to investigate physiological responses occurring during and after triathlons. These observations have led to questions concerning the origin of these responses and their potential influence on the training process.

The specificity and complexity of triathlons requires training programmes to be viewed as a whole, for example, to have a global endurance approach nourished with specific disciplinary modes stimulating a wide variety of biomechanical and physiological responses. ${ }^{[20,21]}$ This variety often generates high training volumes. O'Toole et al. ${ }^{[3]}$ reported weekly training averages of $10.5 \mathrm{~km}$ swimming, $304 \mathrm{~km}$ biking and $72 \mathrm{~km}$ running in a population of experienced male and female triathletes. This training profile is also found in other studies. ${ }^{[1,18,22]}$ The high training volume observed is attributed to the necessity to reach a high performance level in all 3 disciplines. ${ }^{[5]}$ This target may be achieved with a specific training programme in each of the 3 disciplines, that also generates cross-training effects. ${ }^{[18,23]}$ The combination of specific and crosstraining effects in triathlon training may be explained by the involvement of central and peripheral adaptation processes. ${ }^{[24]}$ Indeed, it seems that performance in a specific discipline may benefit, via transfer effects of training, another discipline. ${ }^{[25,26]}$ For example, according to Mutton et al., ${ }^{[27]}$ a training programme combining cycling and running may bring about the same benefits to running performance as a specific running programme. However, these results were obtained only in recreational triathletes and not in a top-level population.

Gradual progression in training generates more stable adaptive responses and offers a greater chance to overcome strenuous race conditions without compromising the athlete's physiological integrity. This is also true for older disciplines, such as long distance running (e.g. marathons) where it appears that adaptation cannot occur without an appropriately progressive training programme. Therefore, identification of the physiological demands specific to the marathon and triathlon will allow an in-depth analysis of the constraints leading to the variation in performance in these 2 disciplines.

\section{Analysis of the Metabolic Constraints in Long Distance Running and Triathlons}

The first stress occurring in triathlon, is probably related to environmental factors, as stress is partly induced by thermal conditions. ${ }^{[28]}$ Indeed, the first factor to face is thermal; both the triathlete and the runner have to contend with heat production to delay hyperthermia and dehydration.

\subsection{Parameters Relating to Dehydration: The Haematocrit}

To avoid incidents of hyperthermia and hypotension, the mechanisms that control homeostasis allow for only minimal physiological variation in terms of body temperature and plasma volume and constituents. However, even during muscular exercise, performed in a neutral environment, thermoregulation requires the production of sweat that may lead to a progressive 'involuntary' dehydration. This dehydration is associated with a drift in the body temperature ${ }^{[29,30]}$ and a marked increase in heart rate.${ }^{[31]}$ During prolonged exercise, Costill 
and Fink ${ }^{[32]}$ noted a 16 to $18 \%$ reduction in plasma volume that corresponded to a $4 \%$ loss in bodyweight. The reduction of plasma volume depends on exercise intensity, nature and ambient conditions, ${ }^{[33]}$ and seems to elicit an increase in $\mathrm{O}_{2}$ demand and, therefore, may affect performance. ${ }^{[34]}$

Endurance training generates lower haematocrit values which in most cases is caused by an increased plasma volume ${ }^{[35]}$ and rarely by haemolysis. ${ }^{[36]}$ Performance in long distance triathlons appears to be inversely related to the haematocrit at rest or after each discipline. ${ }^{[37]}$ The reduction in blood viscosity facilitates capillary circulation ${ }^{[36]}$ and oxygen transport to the active tissues. Raised haematocrit values are classically observed after long distance ${ }^{[38,39]}$ and short distance ${ }^{[2,15]}$ triathlons. Bodyweight loss noted after triathlons indicates a state of dehydration that, at times, requires medical intervention. ${ }^{[28]}$ According to this bodyweight loss, triathletes are still hypohydrated and haemodilute during the race. ${ }^{[40]}$ This phenomenon is often caused by the inability of the athletes to maintain hydration and/or by specific environmental or experimental conditions. Maintaining a normal body temperature, achieved by adequate hydration during the effort, is recognised as a determining factor of triathlon ${ }^{[41]}$ and long distance running performance. ${ }^{[42]}$ The physiological responses associated with dehydration lead to a decrease in the aerobic performance, ${ }^{[43]}$ hence the need to draw particular attention to hydration in triathlons. Moreover, Kreider et al. ${ }^{[41]}$ demonstrated that the combination in continuum of the 3 disciplines generates greater cardiovascular and thermal responses than when these disciplines are performed separately. The authors, therefore, suggested that triathletes include specific training sessions centred on combining the 3 disciplines in their programme, thus stimulating specific physiological responses and adaptations.

\subsection{Parameters Relating to Anaemia: Haemoglobin}

Anaemia may be defined as a decrease in haemoglobin concentration in blood volume, with no alteration of the plasma volume. Haematocrit val- ues and haemoglobin rates that are lower than the norms generally diagnose anaemia. It is the breaking of the balance between erythrocyte production and destruction - erythropoiesis and haemolysis that generates a situation of anaemia. The lowering of blood iron levels, sometimes observed in endurance athletes, may also cause anaemia. ${ }^{[4]}$ The occurrence of haemolysis has often been attributed to abrupt increases in physical exertion by relatively untrained individuals, but is more commonly reported in highly trained long distance runners. ${ }^{[45]}$ In this population, anaemia may appear by means of repeated haemolysis whenever a long duration exercise is performed. ${ }^{[36]}$ The most likely explanation is mechanical breakdown of red blood cells resulting from the trauma of repetitive footstrikes during running. ${ }^{[46]}$ However, haemolysis does not seem to occur in well-trained triathletes, ${ }^{[47]}$ unless they participate in a training session lasting a minimum of 2 hours, and then the degree is related to the duration of exercise. ${ }^{[46]}$ These authors concluded that the incidence of 'sports anaemia' is considerably higher in males competing in long distance triathlons ( $>8$ hours) than it is in males competing at shorter distances or in females competing at either distance. The origin of haemolysis observed after endurance exercise is not entirely understood, but several hypotheses have been put forward. Erythrocyte destruction could have a mechanical origin, that is, the repeated contact of the feet with the ground during running, ${ }^{[36]}$ or could be caused by the increase in cell distortion when the circulatory flow increases as a result of exercise. ${ }^{[48]}$

Other factors that may also explain haemolysis include metabolic acidosis and a rise in circulating catecholamines during exercise that would increase cell membrane instability. Although haemolysis occurs during exercise, the reduction in erythrocyte numbers is only transitory, and erythropoiesis is not altered. In trained individuals, the lowering of haematocrit values may be a result of a rise in plasma volume. ${ }^{[35,48,49]}$ Clinical signs apparently do not accompany these anomalies. Triathletes usually display an anaemia called 'sport anaemia' or 'pseudoanaemia.' ${ }^{[46]}$ For a declared anaemia, an exogenous 
iron supply may stimulate erythropoiesis, but may also have harmful effects, given its role in oxidisation stress. ${ }^{[50]}$ The most important parameter to distinguish 'anaemia' and 'pseudo-anaemia' as a result of deficit iron is ferritin. These metabolic responses, along with plasma hypovolaemia, provoke an increased demand for oxygen in the active muscles to maintain exercise intensity. The physiological changes associated with these responses are partly controlled by the action of catecholamines - an indicator of sympathetic activity - which influence both the metabolic and cardiocirculatory responses and adaptations to exercise.

\subsection{Parameters Relating to the Sympathetic Adrenergic System: The Catecholamines}

The sympathetic adrenergic system plays an active role in the control of cardiac output and in blood volume distribution, thus facilitating substrate transport to working muscles. ${ }^{[51]}$ It is well established that catecholamine levels [e.g. adrenaline (epinephrine), noradrenaline (norepinephrine)] increase with the intensity of muscular exercise, ${ }^{52]}$ exercise duration ${ }^{[53]}$ and hyperthermia. ${ }^{[54]}$ Exercise performed at an intensity above anaerobic threshold leads to a marked increase in catecholamine levels. ${ }^{[55]}$ Plasma catecholamine levels accurately reflect physiological stress and the activity of the sympathetic nervous system. ${ }^{[56]}$ The response produced by this system varies with the tissue considered and with the level of training. During endurance events, exercise duration is the first element responsible for a rise in catecholamine levels during and after exercise. Catecholamines measured during recovery complement the information provided by the variations classically observed at work. ${ }^{[57]}$

Comparing a triathlon with a 24-hour run tends to indicate that the raised adrenaline and noradrenaline levels are caused by exercise duration rather than intensity. ${ }^{[58]}$ However, Hausswirth et al. ${ }^{[2]}$ were able to show that noradrenaline levels were higher at the end of a short distance triathlon than at a run of a similar duration. These authors showed that this result is linked to the higher solicitation of the anaerobic glycolysis occurring during a short distance triathlon versus a long distance run. For long distance events, Sagnol et al. ${ }^{[59]}$ noted that the initial rise in free plasma adrenaline levels recorded after a 10-hour simulated triathlon may be followed by a marked decrease in subsequent days; down to values lower than those observed at rest. The authors related this observation to a possible reduction in the release of adrenaline by the adrenal medulla. This may also indicate an imbalance between adrenaline production and elimination. ${ }^{[60]}$ Guézennec et al. ${ }^{[57]}$ observed that swimming induced higher sympathetic nerve activity than running. This may explain why activation was higher during a multidiscipline event like a triathlon (including a swim) than a single discipline event like running.

\subsection{Endogenous Energy Reserves: Implications for Nutrition}

The sympathetic adrenergic system plays an important role in the control of substrate utilisation by active muscles. ${ }^{[61]}$ It is also essential to note that the exercise duration and associated workload in endurance events necessitate energy and water intake to compensate for the energy expended by the exercise performed. The totality of the endogenous reserves, such as muscle glycogen and muscle lipid, provide fuel for the active muscles during exercise. ${ }^{[62]}$ However, the utilisation of such substrates as blood glucose and free fatty acids increases as exercise continues and endogenous reserves become depleted. ${ }^{[62]}$ During prolonged exercise the decrease in energy efficiency may be explained by modifications in the fuel reserves available to produce energy and/or by the increased participation of the lipid pathway in the energy production process. The latter interpretation was considered by Hausswirth et al. ${ }^{[2]}$ in an experimental study designed to compare a short distance triathlon with a running exercise of the same duration. They observed that blood free fatty acids and glycerol levels were higher at the end of the running bout. It is suggested that runners were using more fat than triathletes during their own exercise. However, it should be noted that there is typically an exogenous glucose supply 
(mainly via drinks) during actual triathlon racing or long distance running that contributes to maintaining a more stable glycaemia. This supply preserves endogenous glucose stocks ${ }^{[63]}$ and may therefore improve performance in marathons ${ }^{[64]}$ and triathlons. ${ }^{[65]}$ Whatever the type of endurance exercise, the ingestion of carbohydrates, together with the appearance of glucose in the periphery during exercise plays a major role in the supply of energy to working muscles. ${ }^{[66]}$ In addition to this, modifications in membrane structures may also affect the efficiency of runners and triathletes.

\subsection{Parameters Relating to Muscular \\ Damage: Creatine Kinase, Lactate \\ Dehydrogenase, Myoglobin}

Damage to striated skeletal muscle is known to be caused by exposure to unusual workloads. This damage may be accompanied by delayed extracellular muscle protein leakage. Eccentric contractions, which generally generate higher muscular tension than concentric contractions, ${ }^{[67]}$ are implicated in exercise-induced muscle damage. ${ }^{[68]}$ Apple et al. ${ }^{[69]}$ studied the variations of different plasma creatine kinase (CK) isoenzymes in the soleus muscle of male runners before and after a marathon and noted that the muscle CK-myoglobin (CK-MB) isoenzyme was significantly higher after the marathon than before. However, no significant correlation was reported between the CK-MB elevation and performance time in this study. Muscular damage, as evidenced by a consistent rise in the plasma level of established markers, has also been reported in highly trained triathletes. ${ }^{[38,39,70]}$ The myoglobin level, considered as a sensitive index of the membrane permeability of muscle cells, ${ }^{[71]}$ increases up to 20 fold of the resting values after a long distance triathlon. ${ }^{[72,73]}$ During the hours following a long distance triathlon, the rise in the myoglobin level was directly related to exercise intensity. ${ }^{[74]}$ Eccentric contraction is a crucial factor in explaining why ultra-endurance running generates more trauma than the combination of the 3 disciplines composing a triathlon, ${ }^{[28,75]}$ despite the similar overall exercise duration of the 2 events. ${ }^{[72]}$ This observation is also confirmed by studies that compared the effects of a marathon and a triathlon of the same duration. ${ }^{[21]}$ While the exact relative contribution of each of the triathlon disciplines to the overall muscular damage at the end of a triathlon still remains unclear, ${ }^{[76]}$ it is no doubt less than that observed following a marathon run, which might explain the higher energy cost noted at the end of a marathon versus a triathlon. ${ }^{[77]}$

The blood levels of a number of muscle damage indicators [CK, lactate dehydrogenase (LDH)] remain elevated for several days after a long distance triathlon. CK levels usually reach a peak 24 hours after the end of a triathlon; ${ }^{[73]}$ this is in accordance with the results obtained in long distance running. ${ }^{[78]}$ Effectively, 5 days after an Ironman distance triathlon the levels of plasma muscle enzymes have still not returned to the initial values. ${ }^{[38]}$

The response of other indirect markers of muscular damage caused by exercise is variable. ${ }^{[79]}$ Major inter-individual differences are noted, independent of factors such as age and local metabolic capacities. Training may also reduce the response of these markers to exercise in humans. ${ }^{[79,80]}$ Although they are widely used, the precision of these markers in the estimation of muscular damage remains questionable. However, muscular damage may be evidenced by a state of articular stiffness and reduction in the capacity to generate forces. ${ }^{[78,81]}$ Limitation in local functional capacities may cause a modification in the biomechanics of running and therefore, alter energy efficiency during endurance sports such as marathons and triathlons.

\section{Alterations in the Energy Cost of Running: A Comparative Analysis of Triathlons Versus Long Distance Running}

\subsection{The Energy Cost of Locomotion}

Within the limits of its validity (50 to $80 \%$ of $\mathrm{VO}_{2 \max }$ ), energy cost estimation appears to be a relevant means of investigating the effects of individual efficiency on performance in various forms of locomotion. ${ }^{[77,82]}$ 
The energy cost of locomotion (i.e. walking, running, cycling) may be defined as the quantity of energy spent per distance unit (expressed in $\mathrm{ml}$ $\mathrm{O}_{2} / \mathrm{kg} / \mathrm{km}$ or in $\mathrm{J} / \mathrm{kg} / \mathrm{km}$ ). ${ }^{[83]}$ Using this perspective, the validity of energy cost depends on the method used to measure the energy expenditure. In experimental conditions, both aerobic and anaerobic metabolism are stimulated, and the estimation of energy expenditure is based on the calculation of the energy equivalent in $\mathrm{O}_{2}\left(\mathrm{EO}_{2}\right)$ and lactate $(\mathrm{Ela}=3 \mathrm{ml} \mathrm{O} 2 \cdot \mathrm{mmol} / \mathrm{L}) .{ }^{[83]}$ However, for efforts partly or totally anaerobic, the determination of energy expenditure strictly related to the anaerobic pathway is difficult to assess. It is dependent upon the ATP, phosphocreatine and muscular glycogen level, the active muscle mass, and the relative validity of the blood lactate level as a reflection of intramuscular lactate production.

Therefore, to be valid, the calculation of energy cost relies on measurements obtained in stable submaximal metabolic conditions, where $\mathrm{VO}_{2}$ is truly representative of energy expenditure per unit of time. In these conditions, several terms are used in the literature to refer to $\dot{\mathrm{V}}_{2}$ : submaximal demand, aerobic efficiency, cost in oxygen, metabolic cost and running economy (for a running effort). When

$\mathrm{V}_{2}$ is related to the work produced, one refers to the concept of energy cost. The most classical mode of calculation was provided by di Prampero in $1986,{ }^{[10]}$ with the following equation:

$\mathrm{Cr}=\left(\dot{\mathrm{VO}}_{2}-\dot{\mathrm{VO}}_{2}\right.$ rest $) \cdot$ speed $^{-1}$

where $\mathrm{Cr}$ is expressed in $\mathrm{ml} \mathrm{O} / \mathrm{kg} / \mathrm{m}$, speed in $\mathrm{m} / \mathrm{sec}$, and $\dot{\mathrm{V}} \mathrm{O}_{2}$ in $\mathrm{ml} \mathrm{O}_{2} / \mathrm{kg} / \mathrm{min}$.

These calculations postulate a perfect linear-

ity in the relationship between $\dot{\mathrm{V}}_{2}$ and velocity, which at present is accepted. It features a stability of the energy cost independently from any increase in speed, within a range of speeds corresponding to 50 to $80 \%$ of $\dot{\mathrm{V}}_{2 \max }{ }^{[6]}$

Therefore, in prolonged efforts such as triathlons and marathons, where the average velocity matches the previously mentioned range of submaximal intensities, energy cost represents the athlete's energy efficiency, and can be considered as one of the determinants of performance. ${ }^{[14,15]}$ Conversely, this index is not physiologically relevant in shorter distance events, where performance is dependent upon the capacity to supply as much mechanical energy as possible during the shortest possible time. This discrimination is confirmed in several studies, where a significant correlation has been found between submaximal $\mathrm{VO}_{2}$ and performance only over long distance events, in running specialists. ${ }^{[11,12,84]}$ In this regard, the reference to energy cost as an index of efficiency for a given task requires the metabolic parameters contributing to its variations to be identified. Therefore, it becomes important to assess the relationship between the performance achieved in a triathlon and a prolonged run and the alterations of this parameter, in order to identify its contribution to performance.

\subsection{Evolution of Energy Cost During Multidiscipline (i.e. Triathlon) Events}

\subsubsection{Components of Performance in Triathlons}

Athletes completing the run segment of a triathlon experience feelings that are not encountered during an isolated run. A number of studies ${ }^{[1,18]}$ have attempted to characterise the physiological alterations occurring during and after this type of activity. Numerous subjective observations from athletes regarding these 2 running modes have led investigators to try and identify the origins of the noted phenomena and their potential consequences on performance. ${ }^{[15,17,20]}$

According to Laurenson et al., ${ }^{[1]}$ factors determining performance in a triathlon are similar to those prevailing in prolonged exercise, whilst for others ${ }^{[18]}$ these factors are primarily driven by the specificity of the activity. Factors such as thermoregulation during exercise ${ }^{[18]}$ and/or the ability to save oneself during the course of a triathlon ${ }^{[1,85]}$ have clearly been identified as factors affecting triathlon performance. According to Sleivert and Rowlands, ${ }^{[20]}$ the $\dot{\mathrm{V}}_{2 \max }$ cannot be used to predict performance within homogenous groups of elite performers: the ability of the triathlete to exercise at a lower percentage of $\dot{\mathrm{V}}_{2 \max }$ for a given sub- 
maximal workload may be especially important to triathlon success. It is well established that the percentage $\dot{\mathrm{V}}_{2 \max }$ used during prolonged exercise constitutes a determining factor in running performance. ${ }^{[8]}$ The run section of a triathlon also seems important in determining overall triathlon performance. Dengel et al. ${ }^{[85]}$ have confirmed that energy cost greatly influences triathlon performance; however, the physiological and/or biomechanical response during the running part of a triathlon is also greatly influenced by the preceding swim and cycle segments. Boone and Kreider ${ }^{[17]}$ have laid the foundations of the estimation of $\mathrm{Cr}$ in running after a cycling session. This study demonstrated the effects of a 3-minute cycling exercise at $80 \%$ of maximum heart rate, on a subsequent 5-minute treadmill run performed at $9.6 \mathrm{~km} / \mathrm{h}$. The authors noted that $\mathrm{Cr}$ was higher during the run performed after the cycle exercise, compared with a single run of a similar duration. It should be noted, however, that the participants were not triathletes but physically active students and the running challenge was considerably slower than that during a competitive triathlon.

Kreider et al. ${ }^{[41,86]}$ further demonstrated that $\mathrm{VO}_{2}$, expiratory flow, heart rate and arterio-venous oxygen gradient were higher at the end of a laboratory triathlon ( $800 \mathrm{~m}$ swim, $40 \mathrm{~km}$ cycle, $10 \mathrm{~km}$ run) than at the end of an isolated $10 \mathrm{~km}$ run. It was concluded that these cardiovascular adaptations were needed to offset the thermoregulatory load imposed before the triathlon run. Results obtained in these 2 studies constitute a most interesting database, however, treadmill running does not recreate the actual outside run conditions. Guézennec et al. ${ }^{[15]}$ decided to compare the ventilatory response during an Olympic-distance triathlon $(1.5 \mathrm{~km}$ swim, $40 \mathrm{~km}$ cycle, $10 \mathrm{~km}$ run) staged in a natural environment and a $10 \mathrm{~km}$ control run performed at the speed of the triathlon run. They confirmed the significantly elevated energy cost of the triathlon run compared with the isolated run $(224$ vs $204 \mathrm{ml} \mathrm{O} / \mathrm{kg} / \mathrm{km}$, respectively) together with a higher ventilatory flow. The authors suggested that kinematic factors such as stride length and frequency could probably ex- plain the decrease in running efficiency, although these were not measured in the study. Hausswirth et al. ${ }^{[2]}$ conducted a similar experiment, where a 45-minute run performed on a track at the end of a triathlon was compared with a 45-minute control run performed at the same speed. The increase in $\mathrm{Cr}$ during the triathlon run compared with the isolated run was confirmed (224 vs $207 \mathrm{ml} \mathrm{O} / \mathrm{kg} / \mathrm{km}$, respectively). To explain this observation, factors such as plasma hypovolaemia and a higher bodyweight loss at the end of the triathlon were suggested; both related to the triathlon duration and specificity. Furthermore, an estimation of stride length conducted during both runs, found that the initial phase of the triathlon run elicited a shorter stride length with an associated higher cadence. This adaptive response is a result of the preceding cycling discipline but progressively disappeared over time and both runs proved very similar in terms of stride length during the terminal phase of the tests. ${ }^{[2,77]}$

Multidisciplinary events, such as triathlons, may present both a bioenergetic and biomechanical specificity associated with the postural changes occurring during the course of the exercise.

\subsubsection{Comparison of the Energy Cost in Middle and Long Distance Running}

Olympic-distance triathlons and marathons are comparable in times ${ }^{[85]}$ (triathlons last between 1 hour 50 minutes and 2 hours, and marathon's best ranges 2 hours 6 minutes to 2 hours 15 minutes). ${ }^{[4]}$ However, the involvement of specific muscle groups in triathlons has led researchers to raise new questions regarding the physiological and biomechanical impact of this still emerging discipline. Three studies $^{[2,77,87]}$ aimed at estimating the $\mathrm{Cr}$ response in running have recently been conducted in triathletes performing a marathon and a triathlon in laboratory and/or environmental conditions. Results indicate that running for 2 hours and 15 minutes induces a notable decrease of the runner's efficacy compared with performing the final run leg of a triathlon of a similar duration. In the terminal phase (the last 45 minutes) of the long distance run, the investigators noted mean $\mathrm{Cr}$ values $18 \mathrm{ml} \mathrm{O} / \mathrm{kg} / \mathrm{km}$ higher than those of the triathlon run. The greater 
ventilatory flow observed in the last part of the marathon run together with the rise in circulating free fatty acids and glycerol, compared with the triathlon run, offers the basis of a consistent explanation of this observation. ${ }^{[2]}$

Movement parameters, such as stride length and/or body angles, may explain the physiological responses noted. Although mean stride length is similar during a triathlon run and a control run, ${ }^{\text {77] }}$ there is a transitional phase immediately after the cycling effort during which the stride is shortened. Furthermore, values noted during this transitory phase are not really different from those noted in the terminal phase of the 2 hour 15 minute run, where stride length regularly shortens until exercise ends. It is apparent that the prior cycling exercise induces modifications in body angles during the subsequent run. This includes a significantly more forward leaning position of the trunk, when compared with the last phase of the 2 hour 15 minute run. The authors attributed the higher $\mathrm{Cr}$ noted during the marathon run to a greater knee extension at heel landing and a greater knee bending during the aerial phase of the stride, compared with the triathlon run. Other elements such as the specificity of muscle contraction mode during the different segments of a triathlon (some of them generating a higher degree of fatigue) may also explain the adaptive $\mathrm{Cr}$ response. ${ }^{[87]}$ As in marathons, triathlons induce muscle damage, as evidenced by the increased plasma levels of specific markers. ${ }^{[38,72]}$ It is established, however, that endurance running generates more trauma than the combination of the 3 disciplines comprising the triathlon. ${ }^{[28,72]}$ This observation is confirmed by comparing marathon and triathlon metabolic ${ }^{21]}$ and/or electromyographic indices. ${ }^{[87]}$

\section{Conclusion}

The various energy cost responses observed during long distance runs and triathlons may only be explained with a holistic multifactorial approach combining physiological and biomechanical processes, as the various studies mentioned in this review tend to demonstrate. This analysis also needs to take the actual specificities of each discipline studied (e.g. marathon, triathlon, duathlon) into consideration. For exercises lasting more than 2 hours, an impairment of running economy is more pronounced at the end of a long distance run compared with a triathlon lasting the same time. This is partly due to the more elevated levels of free fatty acids and circulating glycerol obtained at the end of the long run. Moreover, the significant increase in core temperature and fluid loss occurring during the long run largely explain the decrease of running economy in comparison with the last part of the triathlon. However, further studies are needed to improve our understanding of the underlying mechanisms behind endurance efforts. Particular attention should be focused on investigating the relationship between muscle fatigue indices (using electromyography) and the evolution of efficiency during prolonged exercise.

\section{Acknowledgements}

Special thanks to Shirley Yarde and Darren Smith for their assistance in the english corrections and modifications in the manuscript.

\section{References}

1. Laurenson NM, Fulcher KY, Korkia P. Physiological characteristics of elite and club level female triathletes during running. Int J Sports Med 1993; 14: 455-9

2. Hausswirth C, Bigard AX, Berthelot M, et al. Variability in energy cost of running at the end of a triathlon and a marathon. Int J Sports Med 1996; 17: 572-9

3. O'Toole ML, Hiller WDB, Crosby LO, et al. The ultraendurance triathlete: a physiological profile. Med Sci Sports Exerc 1987; 19: 45-50

4. Boileau RA, Mayhew JL, Riner WF. Physiological characteristics of elite middle and long distance runners. Can J Appl Sports Sci 7: 167-72

5. Zinkgraf SA, Jones CJ, Warren B, et al. An empirical investigation of triathlon performance. J Sports Med 1986; 26:350-6

6. Daniels J. A physiologist's view of running economy. Med Sci Sports Exerc 1985; 17: 332-8

7. Sjödin B, Svedenhag J. Applied physiology of marathon running. Sports Med 1985; 2 (2): 83-99

8. Farrell PA, Wilmore JH, Coyle EF, et al. Plasma lactate accumulation and distance running performance. Med Sci Sports 1979; $11: 338-44$

9. Butts NK, Henry BA, McLean D. Correlations between $\dot{\mathrm{VO}}_{2 \max }$ and performance times of recreational triathletes. J Sports Med Phys Fitness 1991; 31: 339-44

10. Di Prampero PE. The energy cost of human locomotion on land and in water. Int J Sports Med 1986; 7: 55-72 
11. Conley D, Krahenbuhl G. Running economy and distance running performance in highly trained athletes. Med Sci Sports Exerc 1980; 12: 357-60

12. Lacour JR, Padilla S, Barthelemy JC, et al. The energetics of middle distance running. Eur J Appl Physiol 1990; 60: 38-43

13. Morgan DW, Martin PE, Krahenbuhl GS, et al. Variability in running economy and mechanics among trained male runners. Med Sci Sports Exerc 1991; 23: 378-83

14. Morgan DW, Martin P, Krahenbuhl G. Factors affecting running economy. Sports Med 1989; 7 (5): 310-30

15. Guézennec CY, Vallier JM, Bigard AX, et al. Increase in energy cost of running at the end of a triathlon. Eur J Appl Physiol 1996; 73: 440-5

16. Hilliard DC. Finisher, competitors, and pros: a description and speculative interpretation of the triathlon scene. Play Culture 1988; 1: 300-13

17. Boone T, Kreider RB. Bicycle exercise before running: effect on performance. Ann Sports Med 1986; 3: 25-9

18. O'Toole ML, Douglas PS, Hiller WDB. Applied physiology of a triathlon. Sports Med 1989; 8 (4): 201-25

19. Flynn MG, Costill DL, Kirwan JP, et al. Fat storage in athletes: metabolic and hormonal responses to swimming and running. Int J Sports Med 1990; 11: 433-40

20. Sleivert GG, Rowlands DS. Physical and physiological factors associated with success in the triathlon. Sports Med 1996; 22: 8-18

21. Köhler V, Neumann G. Sportmedizinische Untersuchungen bei kombinieren Ausdauerbelastung. Med Sport 1987; 27: 140-3

22. Deitrick RW. Physiological responses of typical versus heavy weight triathletes to treadmill and bicycle exercise. J Sports Med Phys Fitness 1991; 31: 367-75

23. Tanaka $H$. Effects of cross-training: transfer of training effects on $\dot{\mathrm{VO}}_{2 \max }$ between cycling, running and swimming. Sports Med 1994; 18 (5): 330-9

24. Clausen JP. Effect of physiological training on cardiovascular adjustments to exercise in man. Physiol Rev 1977; 57: 779-815

25. McArdle WD, Magel JR, Delio DJ, et al. Specificity on run training on $\mathrm{VO}_{2 \text { max }}$ and heart rate changes during running and swimming. Med Sci Sport Exerc 1978; 10: 16-20

26. Foster C, Hector LL, Welsh R, et al. Effects of specific versus cross-training on running performance. Eur J Appl Physiol 1995; 70: 367-72

27. Mutton DH, Loy SF, Rogers DM, et al. Effect of run vs combined cycle/run training on $\mathrm{VO}_{2}$ max and running performance. Med Sci Sports Exerc 1993; 25: 1393-7

28. Van Rensburg JP, Kielblock AJ, Van der Linde A. Physiological and biochemical changes during a triathlon competition. Int J Sports Med 1986; 1: 30-5

29. Nadel ER, Fortney SM, Wenger CB. Effect of hydration state on circulatory and thermal regulations. J Appl Physiol 1980; 49: 430-7

30. Nielsen B. The effect of dehydration on circulation and temperature regulation during exercise. J Therm Biol 1984; 9: 107-12

31. Sawka MN, Francesconi RP, Young AJ, et al. Influence of hydration level and body fluids on exercise performance in the heat. JAMA 1984; 252: 1165-9

32. Costill DL, Fink WJ. Plasma volume changes following exercise and thermal dehydration. J Appl Physiol 1974; 37: 521-5

33. Van Beaumont WA, Greenleaf JE, Juhos L. Disproportional changes in hematocrit, plasma volume and proteins during exercise and bed rest. J Appl Physiol 1972; 33: 55-61

34. Saltin B, Stenberg J. Circulatory response to prolonged severe exercise. J Appl Physiol 1964; 19: 833-8
35. Convertino VA. Blood volume: its adaptations to endurance training. Med Sci Sports Exerc 1991; 23: 1338-48

36. Selby GB, Eichner ER. Hematocrit and performance: the effect of endurance training on blood volume. Semin Hematol 1994; 31: $122-7$

37. Nagao N, Imai Y, Arie J, et al. Energy intake profile in the triathlon competition by means of cluster analysis. J Sports Med Phys Fit 1991; 32: 201-5

38. Holly R, Barnard R, Rosenthal M, et al. Triathletes characterization and response to prolonged strenuous competition. Med Sci Sports Exerc 1986; 18: 123-7

39. Urhausen A, Kindermann W. Behaviour of testosterone, sex hormone binding globulin (SHBG), and cortisol before and after a triathlon competition. Int J Sports Med 1987; 8: 305-8

40. O'Toole ML, Douglas PS. Applied physiology of triathlon. Sports Med 1995; 19: 251-67

41. Kreider RB, Boone T, Thompson WR, et al. Cardiovascular and thermal responses of triathlon performance. Med Sci Sport Exerc 1988; 20: 285-90

42. Costill DL. Sweating composition and effects on body fluids: the marathon. Ann N Y Acad Sci 1977; 301: 160-74

43. Sawka MN. Physiological consequences of hypohydratation: exercise performance and thermoregulation. Med Sci Sports Exerc 1992; 24: 657-70

44. Cook JD. The effect of endurance training on iron metabolism. Semin Hematol 1992; 186: 49-53

45. Pate R. Sports anemia: a review of the current research literature. Physician Sports Med 1983; 11: 115-26

46. O'Toole ML, Hiller WDB, Roalstad MS, et al. Hemolysis during triathlon races: its relation to race distance. Med Sci Sports Exerc 1988; 20: 272-5

47. Gray AB, Teldford RD, Weidemann MJ. The effect of intense interval exercise on iron status parameters in trained men. Med Sci Sports Exerc 1993; 25: 778-82

48. Karvonen J, Saarela J. Hemoglobin changes and decomposition of erythrocytes during 25 hours following a heavy exercise run. J Sports Med 1976; 16: 171-6

49. Weight LM, Klein M, Noakes TD, et al. Sport anemia: a real or apparent phenomenon in endurance-trained athletes? Int $\mathrm{J}$ Sports Med 1992; 19: 344-7

50. Morris CJ, Earl JR, Trenam CW, et al. Reactive oxygen species and iron: a dangerous partnership in inflammation. Int J Biochem Cell Biol 1995; 27: 109-22

51. Christensen NJ, Galbo H. Sympathetic nervous activity during exercise. Ann Rev Physiol 1983; 45: 139-53

52. Sothmann MS, Gustafson AB, Chandler M. Plasma free and sulfconjugated catecholamine responses to varying exercise intensity. J Appl Physiol 1987; 63: 654-8

53. Galbo H, Holst JJ, Christensen NJ. Glucagon and plasma catecholamines responses to graded and prolonged exercise in man. J Appl Physiol 1975; 38: 70-6

54. Shum A, Johnson GE, Flattery KV. Influence of ambient temperature on excretion of catecholamines and metabolites. Am J Physiol 1969; 216: 1164-9

55. Urhausen A, Weiler B, Coen B, et al. Plasma catecholamines during endurance exercise of different intensities as related to the individual anaerobic threshold. Eur J Appl Physiol 1994; 69: 16-20

56. Péronnet F, Cleroux J, Perrault H, et al. Plasma norepinephrine, epinephrine, and dopamine $\beta$-hydroxylase activity during exercise in man. Med Sci Sports Exerc 1985; 17: 638-88 
57. Guézennec CY, Defer G, Cazorla G, et al. Plasma renin activity, aldosterone and catecholamine levels when swimming and running. Eur J Appl Physiol 1986; 54: 632-7

58. Sagnol M, Claustre J, Pequignot JM, et al. Catecholamines and fuels after an ultralong run: persistent changes after 24-h recovery. Int J Sports Med 1989; 10: 202-6

59. Sagnol M, Claustre J, Cottet-Emard JM, et al. Plasma free and sulphated catecholamines after ultralong exercise and recovery. Eur J Appl Physiol 1990; 60: 91-7

60. Winder WW. Regulation of hepatic glucose production during exercise. Exerc Sport Sci Rev 1985; 13: 1-31

61. Mazzeo RS. Catecholamine Responses to acute and chronic exercise. Med Sci Sports Exerc 1991; 23: 839-45

62. Felig P, Wahren J. Fuel homeostasis in exercise. N Engl J Med 1975; 293: 1078-84

63. Adopo E, Péronnet F, Massicote D, et al. Respective oxidation of exogenous glucose and fructose given in the same drink during exercise. J Appl Physiol 1994; 76: 1014-9

64. Tsintzas OK, Williams C, Singh R, et al. Influence of carbohydrate-electrolyte drinks on marathon running performance. Eur J Appl Physiol 1995; 70: 154-60

65. Millard-Stafford M, Sparling PB, Rosskopf LB, et al. Carbohydrate electrolyte replacement during a simulated triathlon in the heat. Med Sci Sports Exerc 1990; 22: 621-8

66. Coyle EF, Hagberg JM, Hurley BF, et al. Carbohydrate feeding during prolonged strenuous exercise can delay fatigue. J Appl Physiol 1983; 55: 230-5

67. Armstrong RB. Mechanisms of exercise-induced delayed onset muscular soreness: a brief review. Med Sci Sports Exerc 1984; 16: 529-38

68. Stauber WT, Clarkson PM, Fritz VK, et al. Extracellular matrix disruption and pain after muscle action. J Appl Physiol 1990; 69: 868-74

69. Apple FS, Rogers MA, Sherman WM. Profile of CK isoenzymes in skeletal muscles of marathon runners. Clin Chem 1984; 30: 413-6

70. Farber H, Arbetter J, Schaeffer E, et al. Acute metabolic effects of an endurance triathlon. Ann Sports Med 1987; 3: 131-8

71. Driessen-Kletter MF, Amelink GJ, Bär PR, et al. Myoglobin is a sensitive marker of increased muscle membrane vulnerability. J Neurol 1990; 237 (4): 234-238

72. Guézennec CY, Giaoui M, Voignier JP, et al. Evolution des taux plasmatiques de LDH, CPK et myoglobine à l'issue d'une course de $100 \mathrm{~km}$ et d'un triathlon. Sci Sports 1986; 1: 255-63

73. Iwane $\mathrm{H}$. A follow-up study of changes in serum myoglobin and enzyme levels in Japanese triathletes. Ann Sports Med 1987; 3: $139-43$
74. Thomas B, Motley C. Myoglobinemia and endurance exercise: a study of twenty-five participants in a triathlon competition. Am J Sports Med 1984; 12: 113-9

75. Fellmann N, Sagnol M, Bedu M, et al. Enzymatic and hormonal responses following a $24 \mathrm{~h}$ endurance run and a $10 \mathrm{~h}$ triathlon race. Eur J Appl Physiol 1988; 57: 545-53

76. Farber H, Arbetter J, Schaeffer E, et al. The endurance triathlon: metabolic changes after each event and during recovery. Med Sci Sports Exerc 1991; 23: 959-65

77. Hausswirth C, Bigard AX, Guézennec CY. Relationship between running mechanics and energy cost of running at the end of a triathlon and a marathon. Int J Sports Med 1997; 18: 330-9

78. Ebbeling CB, Clarkson PM. Exercise-induced muscle damage and adaptation. Sports Med 1989; 7 (4): 207-34

79. Balnave CD, Thompson MW. Effect of training on eccentric exercise-induced muscle damage. J Appl Physiol 1993; 75: 1545-51

80. Byrnes WC, Clarkson PM, White JS, et al. Delayed onset muscle soreness following repeated bouts of downhill running. J Appl Physiol 1985; 59: 710-5

81. Newham DJ, Mills KR, Quigley R, et al. Muscle pain and tenderness after exercise. Aust J Sports Med 1982; 14: 129-31

82. Brisswalter J, Fougeron B, Legros P. Variability in energy cost and walking gait during a racewalking in competitive race walkers. Med Sci Sports Exerc 1998; 30: 1451-5

83. Di Prampero PE. Energetics of muscular exercise. Rev Physiol Biochem Pharmacol 1981; 89: 144-222

84. Conley D, Krahenbuhl G, Burkett LN, et al. Physiological changes accompanying training. Phys Sports Med 1984; 12 : 103-6

85. Dengel DR, Flynn MG, Costill DL, et al. Determinants of success during triathlon competition. Res Q Exerc Sport 1989; 60: $234-8$

86. Kreider RB, Cundiff DE, Hammet JB, et al. Effects of cycling on running performance in triathletes. Ann Sports Med 1988; 4: $220-5$

87. Hausswirth C, Brisswalter J, Vallier JM, et al. Evolution of electromyographic signal, running economy and perceived exertion during different prolonged exercises. Int $\mathrm{J}$ Sports Med 2000; 21: 429-36

Correspondence and offprints: Christophe Hausswirth, Ph.D, Laboratory of Biomechanics and Physiology, French National Institute of Sport and Physical Education (INSEP), 11, avenue du Tremblay, 75012 Paris, France.

E-mail: christophe.hausswirth@wanadoo.fr 